\title{
The absence of time-out responding by pigeons during shock-correlated stimuli
}

\author{
W. M. HITTESDORF and RALPH W. RICHARDS \\ Colorado State University, Fort Collins, Colorado 80521
}

\begin{abstract}
The purpose of the present experiment was to determine if pigeons would obtain time-out from stimuli associated with independent schedules of intermittent food and electric shock presentation. Few time-outs were obtained from any of the shock-correlated stimuli, but when reinforcement and shock contingencies were removed during one stimulus, i.e., during an extinction component of a multiple schedule, all subjects obtained a large and consistent amount of time-out. A clear correlation between time-out and behavioral contrast, which occurred when one component of the multiple schedule was correlated with extinction but not when it was correlated with shock, was obtained. While the absence of time-outs during shock-correlated stimuli could be explained as generalization of punishment to the time-out key, the present findings might suggest that the time-out response is an unreliable index of stimulus aversiveness.
\end{abstract}

Recent research has shown that organisms will work for periods of extinction (time-outs) that interrupt various schedules of positive reinforcement. For example, pigeons and/or rats have been reported to obtain time-outs from various simple fixed-ratio (Appel, 1963; Azrin, 1961; Dardano, 1973; Thompson, 1964, 1965) and fixed-interval (Brown \& Flory, 1972) schedules, as well as from various component schedules of a multiple schedule of food reinforcement (Rilling, Askew, Ahlskog, \& Kramer, 1969; Terrace, 1968; a multiple schedule requires the successive presentation of two or more independent schedules of reinforcement, each in the presence of a different exteroceptive stimulus). Since many investigators (e.g., Azrin, 1961; Rilling, et al., 1969; Terrace, 1968) consider the time-out response to be an escape response and, thus, a quantitative index of aversiveness, it is surprising that relatively few studies have examined conditions under which time-outs are obtained from a stimulus associated with both positive reinforcement and the known aversive stimulus, electric shock (Azrin \& Holz, 1966). Hearst and his colleagues (Hearst, 1963, 1967; Hearst \& Koresko, 1964) have reported that many rats will obtain time-out from a stimulus associated with response-independent variable-interval schedules of food and shock presentation. Hearst and Sidman (1961) reported that three out of eight rats consistently obtained time-outs from a stimulus responding to which produced food, according to a response-dependent variable-interval schedule, and shock, according to a fixed-ratio schedule. Similarly, Richards and Rilling (1970) found that some pigeons would obtain time-outs during a fixed-ratio schedule of food reinforcement when the 25 th response within the ratio was shocked.

Reprints may be obtained from either author, Department of Psychology, Colorado State University, Fort Collins, Colorado 80521. The authors would like to thank James Starkey for help with the design and construction of the electroshock device.
Yet, data are lacking concerning time-out from a stimulus associated with response-dependent variable-interval schedules of reinforcement and punishment.

Therefore, the purpose of the present study was to determine if pigeons would obtain time-outs from a stimulus correlated with variable-interval schedules of food and shock presentation. If time-outs were obtained, a secondary purpose was to parametrically examine the relationship between duration of shock delay and the frequency of time-out obtained.

\section{METHOD}

\section{Subjects}

Four experimentally naive adult female White Carneaux pigeons, maintained at approximately $75 \%$ of their free-feeding weight were used.

\section{Apparatus}

The internal dimensions of a standard 3-key operant conditioning chamber were reduced to $23 \times 36 \times 36 \mathrm{~cm}$ by inserting into the back of the chamber a black wooden wall. The center key was illuminated by either a green light (S1) or a white light (S2), while the right key was illuminated with a red light. During reinforcement, $3-\mathrm{sec}$ access to mixed grain, the center key light was extinguished and a light within the magazine was illuminated.

Shock was delivered from a constant current device at a .045 -sec duration through electrodes implated around subjects' pubic bones (Azrin, 1959). ${ }^{1}$ Basically, the shocker consisted of a powerstat that controlled the primary of a high voltage transformer to deliver $0-600 \mathrm{~V}$ ac output; the constant current was produced by a $47 \mathrm{~K}$ resistor in series with the output and monitored by a standard meter. Contingencies for shock and reinforcement were programmed by standard electromechanical equipment located in an adjacent room.

\section{Procedure}

After pecking to the center key was shaped, the schedule of reinforcement was gradually increased until a VI 1-min schedule was attained; throughout these sessions as well as the subsequent 1560 -min sessions of VI 1-min reinforcement, the center key 


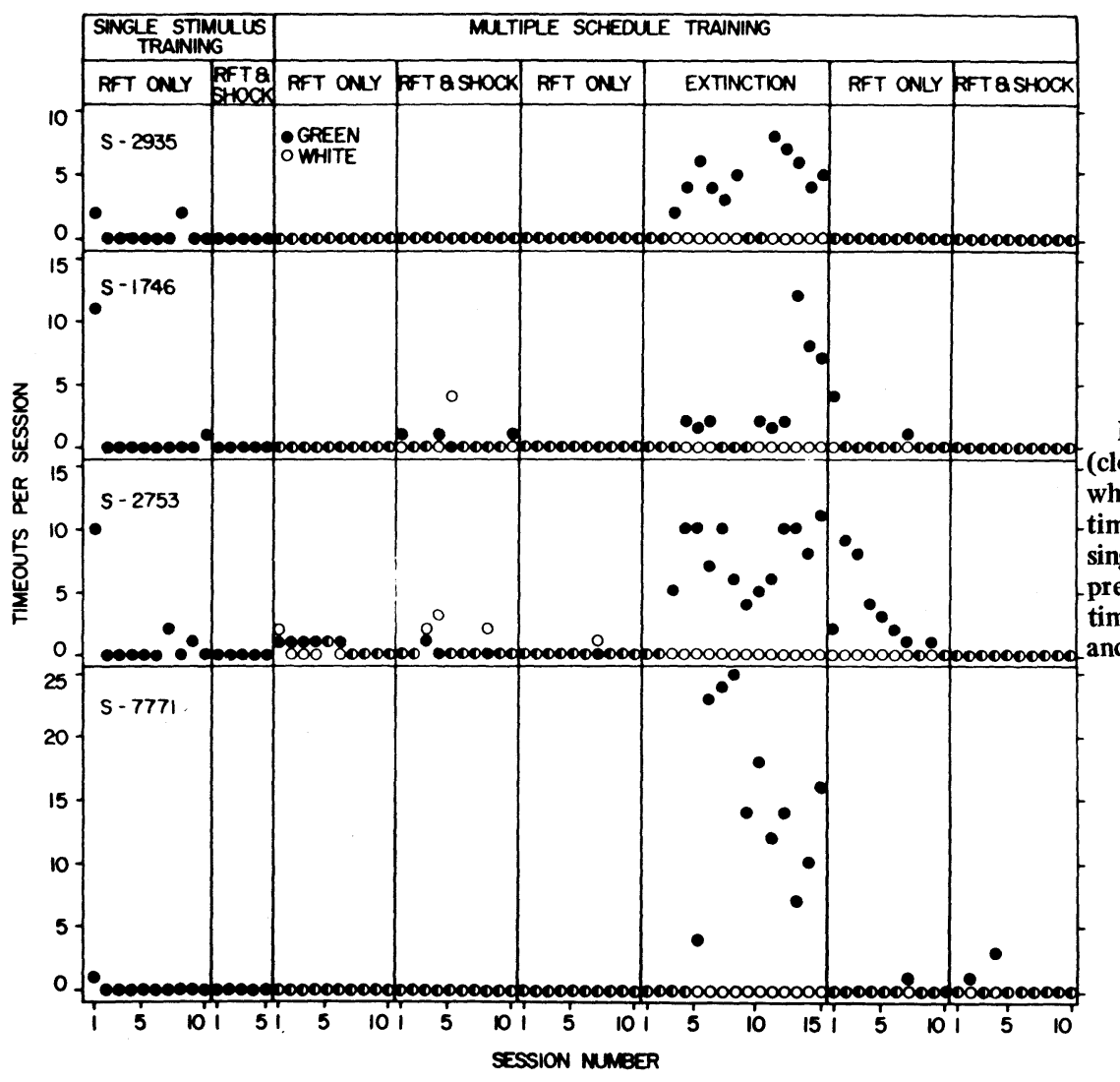

Figure 1. Time-outs obtained from S1 (closed circles; green) and S2 (open circles; white). The left hand section shows time-outs obtained by each subject during single stimulus training when only S1 was presented. The right hand section shows timeouts obtained by each subject during $S 1$ and $S 2$ in multiple schedule training.

was illuminated by $\mathrm{S} 1$. After 5 sessions of VI 1-min reinforcement, the right key (time-out key) was also illuminated. In all of the remaining sessions, a single response to the right key produced a $30-\mathrm{sec}$ time-out, during which the chamber was darkened, the VI tape(s) halted and keypecks were nonfunctional. After 10 sessions with the time-out key available, responding on the center key produced shock according to a VI 2-min schedule; food reinforcement continued to be delivered according to a VI 1-min schedule. The intensity of shock and the duration of the delay in its presentation for each of the subjects were: S-2935, 9-mA shock with a 5-sec delay; S-1746, 3-mA shock with no delay; S-2753, 6-mA shock with a 40-sec delay; and S-7771, 12-mA shock with a 20-sec delay. During the delay period, both key lights were darkened but the houselight remained illuminated; responses during the delay period had no consequences.

For the remaining sessions, the subjects were exposed to various two-component multiple schedules, the components of which were associated with S1 and S2. A session consisted of five alternating, 4-min presentations of $\mathrm{S} 1$ and $\mathrm{S} 2$. Between stimulus presentations, the key lights and the houselight were extinguished and the amber pilot light was illuminated. During this 3-sec interstimulus interval the VI tapes were stopped and the keys were inoperative. If a time-out occurred with less than $30 \mathrm{sec}$ remaining for the center key stimulus, the time-out was terminated with the onset of the interstimulus interval. Each experimental condition during multiple schedule training continued for a minimum of 10 sessions unless response measures indicated a systematically changing baseline over the last five sessions, in which case additional training was given. The various multiple schedules used, in order, were; (1) mult VI 1-min VI 1-min, (2) mult VI 1-min VI 1-min with $\mathrm{S} 1$ also correlated with VI 2-min shock, (3) mult VI 1-min VI 1-min, (4) mult Ext VI 1-min, (5) mult VI 1-min VI 1-min, (6) mult VI 1-min VI 1-min with S1 also correlated with VI 30-sec shock. Shock intensities and delays for subjects remained constant throughout the present experiment except during the final multiple schedule when shock was not delayed for any subject.

To prevent accidental reinforcement and/or punishment for responding on the time-out key, a change-over-delay procedure (Herrnstein, 1961) was employed. Specifically, neither food nor shock was available for $3 \mathrm{sec}$ after the first center keypeck following time-out. If a reinforcer and shock were simultaneously available the first peck produced the reinforcer and the second produced the shock. Due to the programming of the electromechanical equipment, there were time lapses of up to 2 weeks between the various experimental conditions.

\section{RESULTS}

Figures 1 and 2 show, respectively, the number of time-outs obtained by each subject from S1 (closed circles) and S2 (open circles) and the response rates to S1 and S2 during the successive phases of the present study. As the reinforcement contingencies during $S 2$, when presented, were never changed, only the general contingencies associated with $\mathrm{S} 1$ are labeled in these figures. If more than 10 sessions were used in any phase of the present experiment only the last ten sessions are presented. During the 15 sessions of single stimulus training in which the time-out key was operational, subjects obtained few time-outs and none of these were obtained during the five sessions in which center key responding was both reinforced and punished. The center key response rates of three of the four birds during these sessions were 


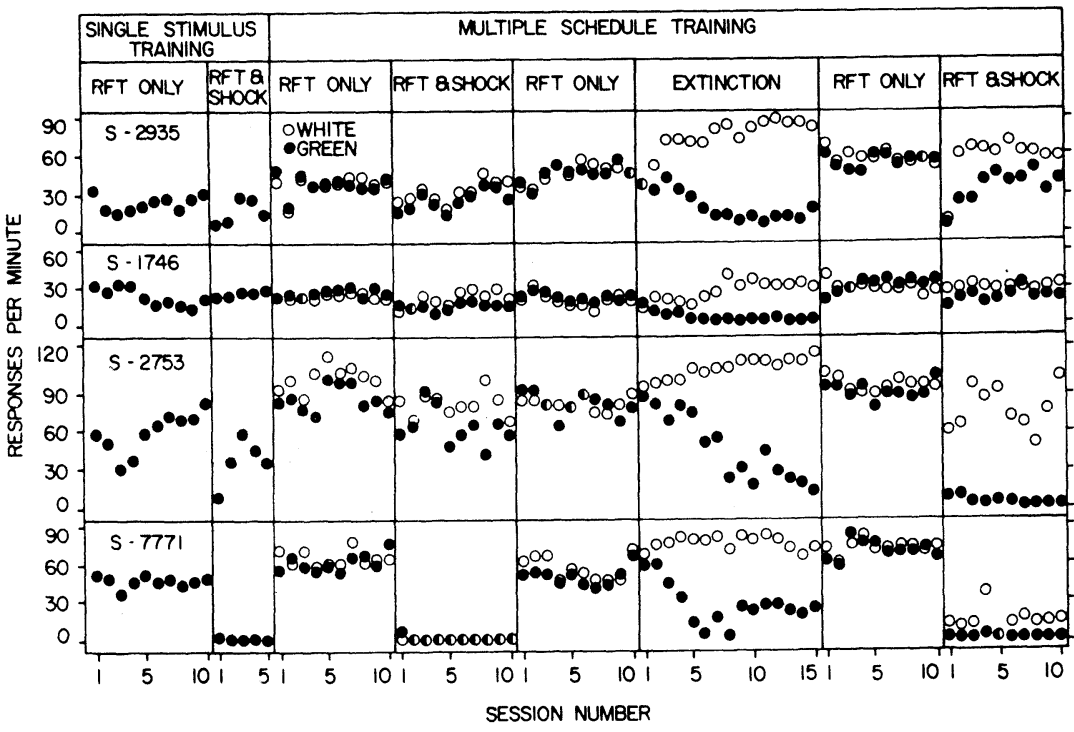

Figure 2. Center-key response rates during S1 (closed circles; green) and S2 (open circles; white). The left hand section shows each subject's response rate to S1 during single stimulus training. The right hand section shows each subject's response rates to $S 1$ and $S 2$ during multiple schedule training. lower than during the previous 10 sessions during which responding was not punished. The magnitude of response reduction varied for each subject possibly due to the various shock intensities and delays that were employed.

Subjects obtained few time-outs during either component of the various multiple schedules except during extinction when the birds obtained a large number of time-outs. In the sessions following the mult EXT V1 1-min phase of the present study time-outs either quickly (S-1746, S-7771, S-2935) or gradually (S-2753) decreased to zero. When compared to sessions where S1 was associated with reinforcement only, center-key responding decreased during both the shock-correlated components and extinction. S-2935, S-2753, and S-7771 also reduced responding during S2 when S1 was associated with VI 2-min shock as did S-2753 and S-7771 when S1 was associated with VI 30-sec shock. S-2935, S-2753, and S-7771 exhibited a clear increase in $\mathrm{S} 2$ responding when $\mathrm{S} 1$ was associated with extinction.

\section{DISCUSSION}

Subjects in the present study reduced their responding to S1 when it was no longer reinforced, i.e., during extinction, and when it was both reinforced and punished. However, only during extinction did subjects obtain a large amount of timeouts. In a similar study, reported near the completion of the present one, Coughlin (1973) found that the shocking of pigeons' responses to a stimulus correlated with extinction reduced the level of time-out responding below that generated by extinction alone. In an attempt to explain the low number of time-outs during a stimulus associated with shock, Coughlin suggested that the response suppression produced by shock may have generalized to the time-out key. In support of this idea, Coughlin also noted that the subjects decreased their rates of responding during each of the two stimuli presented on the center key when responding was punished during only one. While the absence of time-outs in the present study could also be explained as generalization of punishment to the time-out key, the present data might suggest that the time-out response is an unreliable index of stimulus aversiveness. It possibly would be useful in future research to employ a time-out response that is topographically distinct (e.g., a treadle response) from the food reinforced keypeck.

Contrary to the results of the present study as well as Coughlin's study, Brethower and Reynolds (1962) and Terrace (1968) reported an increase in responding during the unpunished component of a multiple schedule, i.e., behavioral contrast was obtained (see Reynolds, 1961). Procedural differences between these studies need to be examined and this discrepancy resolved.

Behavioral contrast has, however, consistently been obtained in a multiple schedule when one stimulus is correlated with reinforcement and the other is correlated with extinction (e.g., Reynolds, 1961; Rilling, et al, 1968; Richards, 1972). Following Premack's (1969) suggestion that contrast results from a change in the aversiveness during one stimulus, Richards (1972) suggested that if behavioral contrast occurs, the stimulus associated with the altered component should possess all the properties of other aversive stimuli, i.e., subjects should learn a new response to escape from the stimulus and the stimulus should serve as an elicitor of aggression and as a punisher of ongoing behavior, and, likewise if contrast is not observed, these properties should not be present. The present results do show a clear correlation between the occurrence of behavioral contrast and time-out. However, further research is needed, possibly examining time-out behavior under conditions in which behavioral contrast is produced by shock, before a definitive conclusion can be made.

\section{REFERENCES}

Appel, J. B. Aversive aspects of a schedule of positive reinforcement. Journal of the Experimental Analysis of Behavior, 1963, 6, 423-428.

Azrin, N. H. A technique for delivering shock to pigeons. Journal of the Experimental Analysis of Behavior, 1959, 2, 161-163. Azrin, N. H. Time-out from positive reinforcement. Science, $1961,133,382-383$.

Azrin, N. H., \& Holz, W. C. Punishment. In W. K. Honig (Ed.) Operant behavior: Areas of research and application. New Y ork: Appleton-Century-Crofts, 1966, Pp. 380-447.

Brethower, D. M., \& Reynolds, G. S. A facilitative effect of punishment on unpunished behavior. Journal of the Experimental Analysis of Behavior, 1962, 5, 191-199.

Brown, T. G., \& Flory, R. K. Schedule-induced escape from fixed-interval reinforcement. Journal of the Experimental Analysis of Behavior, 1972, 17, 395-403. 
Coughlin, R. C. Time-out from a stimulus correlated with the extinction component of a multiple schedule. Learning and Motivation, 1973, 4, 294-304.

Dardano, J. F. Self-imposed time-outs under increasing response requirements. Journal of the Experimental Analysis of Behavior, 1973, 19, 269-287.

Dinsmoor, J. A. A discrimination based on punishment. Quarterly Journal of Experimental Psychology, 1952, 4, 27-45.

Hearst, E. Escape from a stimulus associated with both reward and punishment. Journal of Comparative and Physiological Psychology, 1963, 56, 1027-1031.

Hearst, E. Osciliatory behavior during approach-avoidance conflict. Journal of the Experimental Analysis of Behavior, $1967,10,75-84$.

Hearst, E., \& Koresko, M. B. Self-presentation and self-termination of a conflict-producing stimulus. Science, $1964,146,415-146$.

Hearst, E. \& Sidman, M. Some behavioral effects of a concurrently positive and negative stimulus. Journal of the Experimental Analysis of Behavior, 1961, 4, 251-256.

Herrnstein, R. J. Relative and absolute strength of response as a function of frequencv of reinforcement. Journal of the Experimental Analysis of Behavior, 1961, 4, 267-272.

Premack, D. On some boundary conditions of contrast. In J. Tapp
(Ed.), Reinforcement and behavior. New York: Academic Press, 1969, Pp. 120-145.

Reynolds, G. S. Behavioral contrast. Journal of the Experimental Analysis of Behavior, 1961, 4, 57-71.

Richards, R. W., \& Rilling, M. Time-out and punishment of a single response within a short fixed-ratio schedule of food reinforcem ent. Psychonomic Science, 1970, 19, 51-53.

Richards, R. W. Reinforcement delay: Some effects on behavioral contrast. Journal of the Experimental Analysis of Behavior, 1972, 17, 381-394.

Rilling, M., Askew, H. R., Ahlskog, J. E., \& Kramer, T. J. Aversive properties of the negative stimulus in a successive discrimination. Journal of the Experimental Analysis of Behavior, 1969, 12, 917-932.

Terrace, H. S. Discrimination learning, the peak shift, and behavioral contrast. Journal of the Experimental Analysis of Behavior, 1968, 11, 727-741.

Thompson, D. M. Escape from $\mathrm{S}^{\mathrm{D}}$ associated with fixed-ratio reinforcement. Journal of the Experimental Analysis of Behavior, 1964, 7, 1-8

Thompson, D. M. Time-out from fixed-ratio reinforcement: A systematic replication. Psychonomic Science, 1965,2 , 109-110.

(Received for publication October 17, 1974.) 